www.jdvat.org Review Article

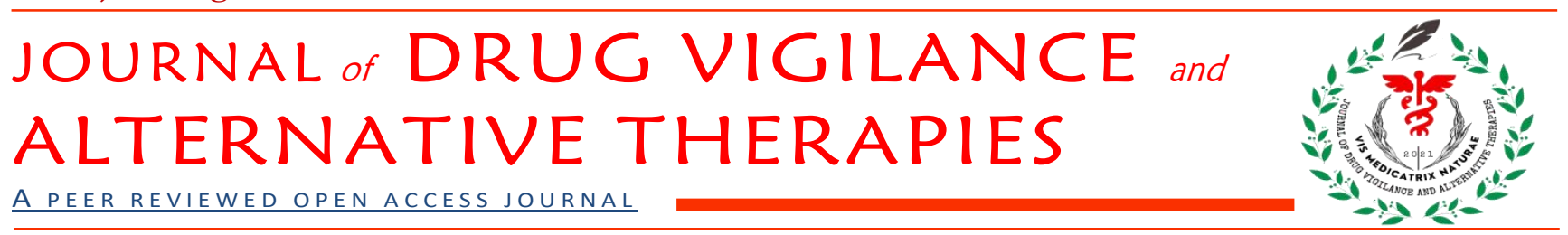

J Drug Vigil Altern Ther. 2021 June 30; 1(2):65-77

DOI: $10.52816 / J D V A T .2021 .1203$

\title{
Curcumin: A Potent Polyphenol with Broad Inhibitory Effect against Different Viral Diseases
}

Poddeti Rathnakar*, Kandavalli Manipriya, Arrani Ashritha

Department of Pharmacology, G. Pulla Reddy College of Pharmacy, Osmania University, Hyderabad, Telangana, India - 500028.

\section{ABSTRACT}

A virus is a non-cellular, neither living nor dead, infection causing agent that replicates in the living cells of the host organisms, from human to bacteria belonging to the family of viridae and genus virus. Curcumin is a polyphenol curcuminoid, a yellow-colored compound obtained from the rhizome of the Curcuma longa. Curcumin has been extensively studied for its anti-microbial, anti-viral, anti-bacterial and many other activities. Various studies have been done to increase its bio-availability and solubility. Curcumin has now been researched in making more potent antimicrobial agents against microbes based on the previous pre-clinical and clinical studies. The present review recapitulated the research studies which determined the anti-viral activity of Curcuma longa.

Keywords: Curcumin, antiviral activity, HIV, hepatitis, SARS-CoV-19, zika virus.

\section{INTRODUCTION}

A virus is a non-cellular, neither living nor dead, infection causing agent that replicates in the living cells of the host organisms, from human to bacteria belonging to the family of viridae and genus virus. ${ }^{1}$ The word virus was derived from Latin, meaning venom and was coined by Dutch microbiologist Martinus Willem Beijerinck (1897). Viruses cannot replicate outside the body of the host because they do not have the machinery for their replication and for this virus infects the cells, replicates with the help of host cells machinery, and forms new viruses. RNA and DNA are the two different genetic materials present in viruses and with a protein coat covering the virus. An interesting fact about the virus is that they crystallize themselves which cannot be done by any other living organism. .,3 $^{2,3}$
Herbal medicines have long been used to treat and prevent many infections caused by microorganisms, including virus. The usage of various herbal plants has been a part of diverse traditions across the world because of their medicinal values, low cytotoxicity, enhanced effectiveness, fewer side effects, and many more benefits. Their preventive and treatment effects on the diseases in modern medicine are increasing in recent years due to the ongoing research. The benefit of most of the herbs is that they have built-in immunestimulating and inflammation-modulating effects. ${ }^{4,5}$ One of the active ingredients among the herbs whose use is from dawn the time is curcumin.

Curcumin (diferuloylmethane) is a polyphenol compound obtained from the plant Curcuma longa, which is largely cultivated \& used in India,

*Corresponding Author: rathnakar0708@gmail.com

\begin{tabular}{l} 
Revised: 25 April 2021 \\
\hline
\end{tabular}

Revised: 25 April $2021 \quad$ Accepted: 15 May 2021

(C)2020. Open access. This article is distributed under the terms of the Creative Commons Attribution-Noncommercial-Share Alike 4.0 Unported License. 
China, and Southeast Asia in diverse food preparations and for medicinal purpose. ${ }^{6}$ It exhibits various pleiotropic properties such as anti-oxidant, antimicrobial, anti-tumor, antiinflammatory, anti-angiogenic, anti-proliferative \& anti-carcinogenic activities. ${ }^{7}$ C. longa rhizome is used as an antimicrobial agent and also as an insect repellent. Curcumin is used in developing skin gels and other products for the skin diseases occurring and also for the dressing of the wounds. ${ }^{8}$ Though curcumin has been effective against various diseases the drawback is its poor bioavailability which has been worked extensively in recent years to improve its absorption, metabolism, and elimination. ${ }^{9}$

Among the antimicrobial activity, curcumin has antiviral, antifungal, antimalarial and antibacterial activities. With the clinical trials performed on humans and found that a high dose shows desirable antimicrobial property, curcumin has now been researched in making more potent antimicrobial agents against microbes. ${ }^{10}$ The present review discusses the applications of curcumin as an antiviral agent towards various viruses as a natural antiviral agent.

\section{CURCUMIN AS ANTIVIRAL AGENT}

Curcumin was considered for its antiviral properties for the first time around the 1990s when it was found that it could prevent the protease of human immunodeficiency virus (HIV) virus in vitro with $100 \mu \mathrm{M}$ inhibitory concentration $\left(\mathrm{IC}_{50}\right) .{ }^{11}$ Numerous studies have been done to know the antiviral properties against various viruses with RNA and DNA genomes. Curcumin exerts its action by inhibition of cell signaling, effect on cellular enzymes, cell adhesion, and angiogenesis. Curcumin was shown to induce apoptosis, reduce cytotoxicity, inhibit the replication of viral genes and affect gene transcription which makes it a potent drug for usage in chemotherapy to treat cancer. ${ }^{12}$

\section{APPLICATION OF CURCUMIN IN DIFFERENT VIRAL DISEASES}

\subsection{Chikungunya Virus}

Chikungunya (CHIKV) is a mosquito-borne viral illness, caused by the chikungunya virus and it was first described in the year 1952 during the outburst in Southern Tanzania. It is an RNA virus, belonging to the family Togaviridae. Chikungunya virus can cause fever, severe joint pains, muscle pain, swelling of joints, headache, nausea, fatigue, rash. There is no vaccine or drug against the virus, but the treatment is mainly focused on relieving the symptoms of the disease. ${ }^{13}$

Curcumin's antiviral properties were investigated by Von Rhein et al. in 2016 on chikungunya virus, wherein the Human embryonic kidney (HEK) 293T cells were treated with a replicating luciferase-tagged CHIKV (CHIKV-luci) with a low Multiplicity of Infection (MOI) of 0.06 in the presence of the Boswellia serrata gum resin extract. Boswellia serrata gum resin extract compounds obstructed the entry of CHIKV Env-pseudotyped lentiviral vectors and inhibited the infection caused by CHIKV in vitro. Vesicular stomatitis virus vector particles and viral infections were also inhibited which shows the broad antiviral activity of curcumin. With the concern of the author on the bioavailability of the curcumin, it can used as a base structure in designing drugs which are more effective or which enhances the antiviral property can be developed, and curcumin can be used as a topical agent on skin and can be applied after the mosquito bite. ${ }^{14}$

\subsection{Dengue Virus}

Dengue fever (DENV) is a mosquito-borne viral illness triggered by a Flaviviridae virus. There are four different species (DENV-1, DENV-2, DENV-3, DENV-3, DENV-4) that have spread across the world. These mosquitoes act as a vector for various other diseases such as chikungunya, zika virus, and many more. It was seen that people who have recovered from the infection are believed to provide lifelong immunity against that serotype. ${ }^{15}$

Balasubramanian et al., 2019 developed curcumin and four analogues and used a cellbased assay to assess in vitro protease activity and replication inhibition. It was noted that curcumin and other analogues inhibited viral protease 
activity. Curcumin had less inhibitory activity when compared to its four analogues and these chemicals only moderately reduced replication of the DENV2 reporter replicon construct, with cyclohexanone and acyclic curcumin analogues outperforming genuine curcumin. Curcumin inhibits DENV was due to its effects on cellular lipid metabolism. ${ }^{16}$ Lim et al.,2020 found that curcumin acts as a non-competitive inhibitor for NS2B-NS3 protease without changing $\mathrm{Km}$ and changing Vmax. ${ }^{17}$

Lima et al., 2017 performed molecular docking between the nonstructural protein 1 (NS1) protein and the two curcuminoids to know that this might be a potentially active agent against the dengue virus. It was noticed that in the anchorage of NS1 with the curcumin ligand, the interactions between them resulted in a lower value for the distance ( $3.5 \AA$ ) was the binding of the $\mathrm{H} 6$ of the curcuminoid linked to phenylalanine 565 of the $\mathrm{E}$ chain of the protein. It was noticed that curcuminoid ligands showed significant results because their molecules interacted well with the receptor site of the protein. 18

Curcumin and its derivative Pentagamavunon-0 (PGV-0) were tested against Dengue-2 by Marbawati and Umniyati in 2015. The high safe concentration of curcumin against vero cells were $6.25 \mathrm{ppm}$ and $1.5625 \mathrm{ppm}$ for PGV-0. Curcumin and PGV-0 were tested for immunocytochemistry for both incubation periods ( 1 and 3 days) showed no remarkable changes and the Reverse transcriptase-Polymerase chain reaction test (RTPCR) showed that the PGV - 0 is more potent antiviral agent than curcumin. ${ }^{19}$

Carneiro et al., 2017 investigated the molecular docking and characterisation of curcumin and monodimethylcurcumin ligands, as well as the dengue virus 5B1C protein (PDB code) (DENV-4). And these molecular docking results showed a correlation with the activity values of the compounds, which confirmed the importance of the residues for DENV-4 activity. It can be noted that curcumin shows a greater effect in the treatment of dengue. ${ }^{20}$
In a study published in 2017, Ichsyani et al. evaluated the effects of $C$. longa extract as a DENV-2 antiviral in mice infected with DENV-infected Huh7it-1 cells. After 6 hrs and 24hrs of infection, in the treatment group, the titer levels of DENV mice were found to be decreased when compared to that of control group. It was observed that the titer of DENV from the curcumin treated group showed a decrease after 6 hours and was not noticed at 24 hours after infection. It was observed that Curcumin longa reduced virus in mice. ${ }^{21}$

\subsection{Ebola Virus}

The Ebola virus produces an acute, severe, and fatal infection that causes extensive internal and external hemorrhage, ultimately leading to organ failure, and there is currently no therapy available. In the final stages of Ebola infection, there is an overproduction of the cytokine by the immune system present in the body. It has been found that curcumin blocks cytokine release. Curcumin suppresses the cytokine release, and this correlates with the clinical advance research in the experimental models, wherein the excess production of cytokine plays a remarkable role in mortality. 22,23

Abe et al., 1999 investigated whether curcumin suppresses the production of inflammatory cytokines by human peripheral blood monocytes and alveolar macrophages. It was found that curcumin inhibited interleukin, monocyte inflammatory protein-1, interleukin- $1 \beta$, monocyte chemotactic protein-1, and tumour necrosis factor- $\alpha$ production by $4 \beta$ phorbor $12 \beta$-myristate$13 \alpha$ acetate (PMA)-stimulated monocytes in a concentration-dependent manner and at a concentration of $10 \mu \mathrm{M}$, curcumin showed greater inhibition in the production of cytokines by PMAstimulated monocytes and alsolipopolysaccharide stimulated (LPS)-stimulated monocytes. $^{24}$

To know the inhibitory action of curcumin and its derivatives on the viral proteins of the Ebola virus, an in-silico approach was done by Noor et al., 2017. It was noticed that curcumin binds to 
viral protein (VP) 40 with a high binding affinity of $-6.3 \mathrm{Kcal} / \mathrm{mol}$. Curcumin forms hydrogen bonds with residues ALA128 and ALA130 to inhibit VP40 and non-covalent interactions with PR0131 PR0165 GLU160 GLN159. Curcuminoids inhibition on VP24 can halt the formation of a functional nucleocapsid and dissuade viral infection. Bisdemethoxycurcumin binds to glycoprote in with a binding affinity of -7.1
Kcal/mol. LEU593 ARG596 bind with bisdemethoxycurcumin by forming hydrogen bond and other non-covalent interactions with TRP597 ILE603 \&ARG596. It can be observed that the glycoprotein gets destabilized when it binds with curcuminoids and the fusion of viral membrane with the cells of the host is prevented. 25

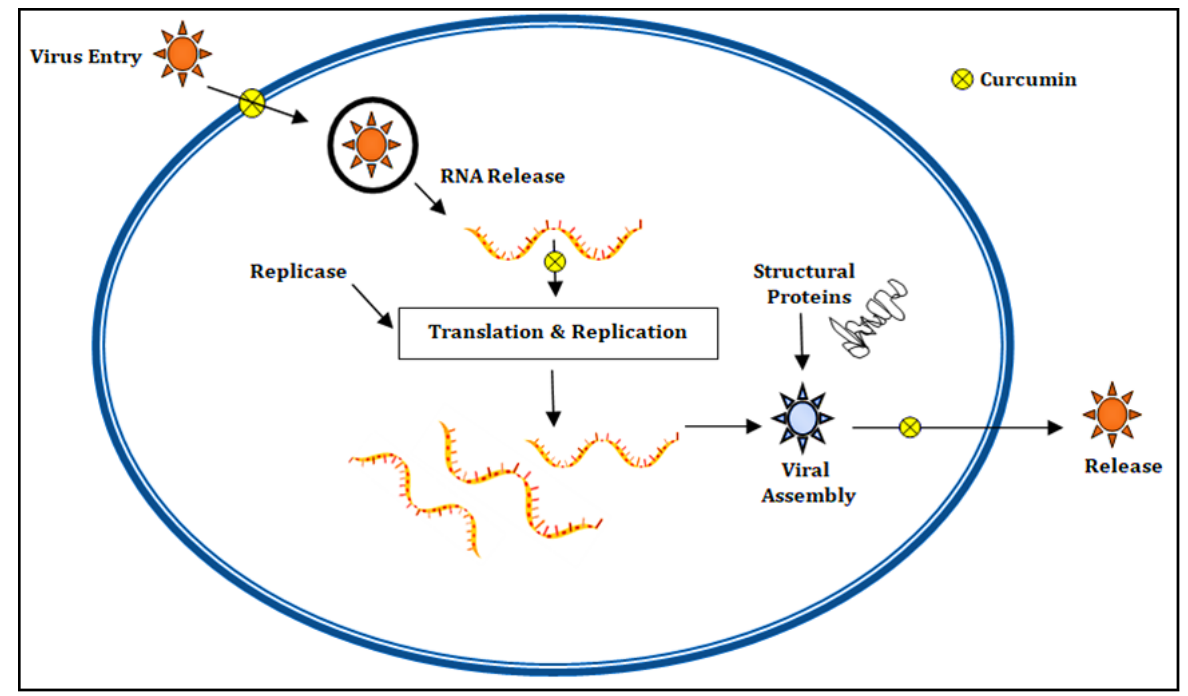

Fig. 1: Inhibition of anti-viral activity of curcumin in the host cell

\subsection{Epstein-Barr Virus}

The double-stranded DNA Epstein-Barr virus (EBV) is also called human gamma herpes virus 4 , belonging to the herpes family. EBV infects the B cells of the immune system and epithelial cells. There is no vaccine against the EBV viral infection. ${ }^{26}$

Curcumin at $15 \mathrm{M}$ concentration significantly reduced induction of $B a m H$ fragment $\mathrm{Z}$ left frame 1 (BZLF1) protein by 12-0-tetradecanoylphorbol13-acetate (TPA) at 72 hours, according to Hergenhahn et al., 2002, which is a consequence of inhibition of transcription. Curcumin also inhibited the BZLF1 mRNA induction by each of the three major EBV inducers and this might be due to the intermediate steps in all the three pathways of the EBV induction are sensitive to curcumin or the pathway-specific elements might have collaborated with curcumin-sensitive AP-1 sites in Raji-DR-LUC cells. ${ }^{27}$

Liu et al., 2019 investigated the effects of curcumin on the viability of nasopharyngeal cancer cells, which were assessed using the Cell
Counting Kit-8 (CCK-8) for positive responses to EBV, HONE1, and HK1-EBV cell proliferation after the medication was administered. It was found that the curcumin reduced the viability of the HONE1 cells in a dose-dependent and also in a time-dependent manner. The data showed that curcumin could remarkably reduce the EBV+ Nasopharyngeal Carcinoma (NPC) cell viability and not for the Human Umbilical Vein Endothelial (HUVE) and Human Kidney (HK2) cells. ${ }^{28}$ Also, Hergenhahn et al., 2002 found that the HK1- EBV and HONE1 cells treated with curcumin showed that curcumin decreased the production of progeny virion, inhibit the EBV latent and lytic replication in HK1-EBV and HONE1 cells. ${ }^{27}$

\subsection{Hepatitis Virus}

Hepatitis is a liver inflammation that can be selflimiting or can develop to fibrosis (scarring), cirrhosis mortality, and even pandemics and epidemics. It is generally caused by the hepatitis virus and there are 5 different hepatitis viruses i.e., type A, B, C, D \& E. Studies have been done immensely on its effectiveness against hepatitis, 
and curcumin has inhibited the virus pathway and the mechanism with which virus propagates in the body. ${ }^{29}$

\subsubsection{Hepatitis A Virus}

Patwardhan et al., 2020 used curcumin to inactivate the Hepatitis A (HAV) virus, which was heat sensitive. It was noticed in Fetal Rhesus Monkey Kidney (FRhK-4) cells and Lilly Laboratories Cell-Monkey Kidney 2 (LLC-MK2) cells that curcumin $(0.015 \mathrm{mg} / \mathrm{ml})$ treatment reduced D-values of HAV when juxtaposed with the D-values of HAV in PBS singly. It was arduous in getting a remarkable effect of the antiviral activity of the extracts in a short period of time. ${ }^{30}$

\subsubsection{Hepatitis B Virus}

Kim et al., 2009 investigated the antiviral impact of C. longa extract (200 and $500 \mathrm{mg} / \mathrm{L})$ on Hepatitis B virus (HBV) replication in HepG 2.2.15 cells in vitro. ELISA was used to evaluate the level of HBsAg secretion. The extracellular release of HBV particles from HepG 2.2.15 was remarkably impeded due to the treatment of the $C$. longa extract and it was observed that $C$. longa extract remarkably subdue the replication of HBV. $C$. longa extract showed $80 \%$ inhibition to the secretion of HBsAg. It is noted that the subduing of HBV replication by $C$. longa extract is most likely the outcome of the suppression of HBV RNA transcription. It was observed that the regulatory mediator p53 protein is majorly required for the anti-HBV activity of $C$. longa extract.

The HBV transcription which was subdued by the activity of $C$. longa extract in HepG 2.2.15 cells was reinstated due to the expression of the dominant-negative mutant p53 protein. It was observed that the mRNA level of the viral polymerase gene reduced and it was noted that the repressed transcription of the HBV X protein (HBx) gene was significantly reinstate by dominant-negative mutant p53 protein. From the data of the research, the CLL extract can be used as a secure herbal medicine in the treatment of liver diseases which are induced by HBV infection because it did not showed any cytotoxicity. ${ }^{31}$

Wei et al., 2017 performed an experiment on whether curcumin inhibits HBV replication and expression, HepG 2.2.15 cells were treated with various concentrations of curcumin and the cytotoxicity was evaluated. It was observed that there was major decrease in the covalently closed circular (cccDNA) (75\%), and mRNA (24\%) and the HBV replication intermediates when evaluated with the help of RT-PCR and Southern blot experiments. They also studied the inhibition of Hepatitis B virus by reducing the histone acetylation by curcumin with the help of histone deacetylase inhibitors, sodium butyrate, and Trichostatin A (TSA). It was observed that when cells were administered with curcumin and sodium butyrate, HBsAg and cccDNA levels were increased by $31.3 \%$ and 2.4 -fold respectively. ${ }^{32}$

\subsubsection{Curcumin on Concanavalin A (Con A)-}

\section{Induced Hepatitis}

Curcumin pretreatment protects mice from Concanavalin A (ConA)-induced liver damage, according to Wang et al., 2012. Curcumin was intraperitoneally administered to mice $2 \mathrm{hrs}$ before Con A injection. It was noticed that serum Alanine Aminotransferase (ALT) levels were remarkably increased in mice after Con A administration and curcumin pretreatment remarkably attenuated Con A-induced elevation of serum ALT. Mice pretreated with curcumin showed minor liver damage and increased the survival of mice. Curcumin treatment reduces hepatocyte apoptosis, inhibits HMGB1 releasing and expression, and lowers inflammatory cytokine release in Con A-induced hepatitis, according to the findings. ${ }^{33}$

\subsubsection{Hepatitis C Virus}

Curcumin's effects on the intracellular replication of the Hepatitis C virus (HCV) genome were studied by Kim et al. in 2010. Curcumin and interferon-alpha (IFN- $\alpha$ ) exerted remarkable inhibitory effect on the replication of HCV. It was observed that the replication of HCV was remarkably suppressed by curcumin in vitro and curcumin can be further studied as a potent novel anti-HCV reagents. ${ }^{34}$

\subsection{Herpes Simplex Virus}

Herpes simplex virus type-1 (HSV-1) or herpes simplex virus type-2 (HSV-2) are the causative 
agents for herpes simplex virus. HSV-1 is transmitted due to oral-to-oral contact or oralgenital contact which causes genital herpes. Administration of antiviral drugs shows an effect on the virus and reduces the severity of the infection but does not offer a cure to the infection. ${ }^{35}$

Curcumin, a phenolic molecule, was found to have anti-herpetic activity against HSV-1 by Kutluay et al., 2008. In plaque assay, it was found that curcumin reduced the lytic infectious cycle of the virus and decreased the ability of the cells to reinforce the HSV-1. Curcumin treatment reduced the ability of the cells to reinforce the HSV-1 virus and slow down the process but it could not block the replication. It Curcumin had a more direct role in inhibiting the Immediate early (IE) gene transcription which thereby reduces the ability of the virus to perform its lytic infectious cycle. ${ }^{36}$

After 12 hours of post-infection, curcumintreated HSV-1 infected vero cells and HSV-1 infected vero cells showed that curcumin treatment prevents viral production in the cells and affects the replication cycle of the virus. The study indicated that curcumin inhibits the replication in HSV-1 and HSV-2 cells and thereby causes a hurdle in the lytic cycle of the virus. ${ }^{37}$ Also, Zandi et al., 2010 studied the HSV-1 antiviral activity of curcumin and it was found that curcumin showed a significant antiviral effect on the HSV-1 in the Vero cell culture. ${ }^{38}$

Curcumin's anti-herpetic efficacy was studied by Ferreira et al. in 2015 in primary genital epithelial cells wherein it was found that at a concentration of $5 \mu \mathrm{M}$ of curcumin decreased the shedding of HSV-2 by 1000 -fold and at a concentration of $50 \mu \mathrm{M}$ of curcumin there was no HSV-2 virus in the supernatants of the cell vultures. And genital epithelial cells were pretreated with nuclear factor kappa light chain enhancer (NF-kB), then infected the cells with HSV-2, it was found that the NF-kB inhibitor pyrrolidine dithio-carbamate significantly blocked the shedding of virus in primary genital epithelial cells when exposed to HSV-2.39

\subsection{Human Adeno Virus}

Adenovirus (HAdV) is a double-stranded DNA virus that is non-enveloped and belongs to the Adenoviridae family. This virus may infect a wide range of hosts. There is no antiviral drug to treat adenoviral infections and the treatment is based on the symptoms. ${ }^{40}$

Curcumin was tested at different doses for antiadenoviral activity in A549 cells infected with HAdV-5 at a MOI of 10 and 1 hour after infection by Jennings \& Parks, 2020. It was found that there was a dose-dependent reduction in the quantity of Early $1 \mathrm{~A}(\mathrm{E} 1 \mathrm{~A})$ protein in HAdV-infected cells. Treatment of the infected cells with $50 \mu \mathrm{M}$ of curcumin for a period of $8 \mathrm{hrs}$ of infection showed that it prevented the expression of the E1A and when treated with curcumin for $1 \mathrm{hr}$ of infection, did not reduce the E1A protein showing that curcumin does not inactivate the virus or prevent the internalization. 41

\subsection{Human Cytomegalovirus}

Cytomegalovirus (CMV) is a double-stranded DNA virus belonging to the family Herpesviridae. Newborns infected before birth, infants who are infected after birth or after a short time, people who have a weak immune system and people suffering from Human immune deficiency virus (HIV) are more likely to show symptoms. ${ }^{42}$

Curcumin significantly reduced the increase of protein production of Hsp90 by Human cytomegalovirus (HCMV) in a dose-dependent manner, according to Lv et al., 2015. Targeting Hsp90 provides a method for the treatment of infection. This increases the endurance rate of the host cells.

The in vitro study showed selective antiviral activity of curcumin against HCMV. Curcumin could decrease the load of HCMV DNA and it was observed that curcumin had different activity against HCMV in vitro after $48 \mathrm{hrs}$ of treatment. This study indicates that curcumin might have the ability to inhibit the replication of HCMV DNA and curcumin could decrease the number of apoptosis of the infected cells. ${ }^{43}$

Lv et al., 2014 used flow cytometry to assess the effect of curcumin on HCMV-infected human 
embryonic lung fibroblast (HELF) cell cycle. This study indicated that curcumin significantly reduced the HCMV immediate early antigen (IEA), UL83A expression, TNF- $\alpha$, IL- 6 , secretions and recovered cell proliferation to normal level in HELF cells infected with HCMV.44

Curcumin's antiviral activity was investigated by Lv et al., 2020, who treated cells with CMV for 48 hours. Human umbilical cord vein endothelial cells and mouse embryo fibroblast cells were observed to have less cytopathic effect in the model group when compared with the normal control group after treatment with different dosage of curcumin on the infected cells. The results showed that curcumin inhibited the CMV replication, their proliferation, reactive oxygen species production as well as the cytokines. ${ }^{45}$

\subsection{Human Immunodeficiency Virus}

The Human Immunodeficiency Virus (HIV) are two species of lentivirus that infect humans and with time they cause acquired immunodeficiency syndrome (AIDS) which is a condition wherein, there is a failure of the immune system causing life-threatening infections and cancers to thrive in the body. Curcumin is been under study for its anti-viral properties and immensely studies have been done on its anti-viral effect on HIV. Studies reveal that curcumin can inhibit HIV in various mechanisms and biological steps. ${ }^{46}$

Curcumin and its compounds suppress transactivation, according to Barthelemy et al., 1998. Henrietta Lacks (HeLa) H12 cells containing the bacteria lacZ gene under the control of HIV1 Long terminal repeat (LTR) was used. At $10 \mathrm{nM}$ concentration, only $30 \%$ of inhibition was seen, and at $1 \mathrm{nM}, 35 \%$ of inhibition was obtained which is 10 times lower than $10 \mathrm{nM}$. It was observed that $\mathrm{C}_{1}$ (hexahydrocurcumin) at 1 nM inhibited Tat-induced transactivation by $54 \%$ and at the same concentration of $1 \mathrm{nM}$ curcumin showed just $35 \%$ of inhibition. No significant differences were observed between curcumin and $\mathrm{C}_{1}$ at 10 and $100 \mathrm{nM}$ and $\mathrm{C}_{2}$ (ally-curcumin) was observed to be inactive. On the other hand, $\mathrm{C}_{3}$ (tocopheryl-curcumin) exhibited the most inhibition activity, 70\% inhibition at a concen- tration of $1 \mathrm{nM}$, and at the same concentration of 1 nM, curcumin only showed $35 \%$ of inhibition. 47

Kumari et al., 2015 investigated the efficacy of curcumin and curcumin A in inhibiting HIV-1 infection in one cycle. CEM-T cells were cultured and infected with vesicular stomatitis virus glycoprotein (VSVG)-pseudotyped HIV-1 pNL4-3 virus expressing luciferase in place of nef (HIV-1 Luc). The cells were treated with the compounds for $24 \mathrm{hrs}$ and luciferase activity was measured, which is an indicator of HIV-1 replication. It was noticed that one round of HIC-1 infection was equally inhibited by curcumin and curcumin $\mathrm{A}$.

Primary Peripheral blood mononuclear cells (PBMCs) were activated by treatment with Phytohemagglutinin (PHA) and IL-2, and they were infected with HIV-1 Luc 24hrs and then treated with curcumin or curcumin for $24 \mathrm{hrs}$. It was observed that curcumin and curcumin A inhibited HIV-1 infection, and curcumin A was more potent than curcumin. It was noted that curcumin A inhibits one round of HIV-1 infection when compared to curcumin in CEM-T cells which showed more potent activity in primary PBMCs and also it was noticed that curcumin A showed a greater therapeutic window in CEM-T cells and PBMCs. 48

\subsection{Human Papilloma Virus}

The human papillomavirus is a DNA virus belonging to the family Papillomaviridae. Patients infected with HPV do not show symptoms and most of them resolve within a span of 2 years. In severe cases, HPV infection persists for a long time and causes precancerous lesions, and these lesions later develop into cancer in the body parts such as the cervix, vagina, penis, mouth, tonsils. There is no proper treatment for the HPV infection and the body's immune system clears the virus. 49

Curcumin modulated the expression of the HPV viral oncogene expression, according to Divya and Pillai, 2006 wherein the total RNA was extracted from the HeLa and SiHa cells which were treated with different concentrations of curcumin for 24hrs. Reduced expression of HPV-18 E6 and E7 genes were found in HeLa cells when treated with curcumin. In the case of detection of oncoproteins, 
SiHa cells HPV-16 E6 and E7 expression when treated with the curcumin and in HPV-18 E6 and E7 proteins reduced with curcumin treatment. ${ }^{50}$

\subsection{Kaposi's Sacroma-Associated Herpes Virus}

Kaposi's sarcoma-associated herpes virus (KSHV) is a double-stranded DNA virus. It is the ninth known human herpes virus and it is officially called Human gamma herpes virus 8. Antiviral drugs such as ganciclovir are used as they target the replication of the virus and prevent the development of the virus; these are of no use when the tumor has already developed before. ${ }^{51}$

Li et al., 2019 investigated whether curcumin inhibits the redox function of Apurinic/ apyrimidinic endonuclease 1 (APE1). Electrophoresis mobility shift assay experiment was performed and it was observed that curcumin inhibit APE1 redox function, Kaposi's SarcomaAssociated Herpesvirus (KSHV) lytic replication by inhibiting the TPA-induced AP-1 pathway andregulator of transcription activation (RTA) expression. Curcumin significantly blocked the reactivation of the KSHV in a dose-dependent manner and the expression of delayed-early gene K8. 52

\subsection{Norovirus}

Norovirus (NoV) is a single-stranded water-borne RNA virus that causes acute gastroenteritis. Norovirus is a non-enveloped virus and it belongs to the family Caliciviridae. Norovirus is a highly contagious infection. There is no treatment for norovirus infection and treatment is considered by preventing dehydration. ${ }^{53}$

Curcumin substantially inactivated Murine Norovirus (MNV-1) according to Wu et al., 2015, who investigated the photodynamic activity of blue-light activated curcumin against MNV-1. The inactivation of MNV-1 was not found to differ significantly between blue-light irradiation alone $(\mathrm{L}+\mathrm{S}-)$ and the negative control (L-S-). Transmission electron microscopy (TEM) was used to examine the ultrastructural morphology of MNV-1, and tiny bits of debris from damaged MNV-1 were found in the photodynamically activated curcumin-treated group at $10 \mathrm{M}$ concentration. For six hours, live oysters were exposed to MNV-1, which accumulates norovirus in their intestines. The virus was removed from the intestines, and a plaque assay was performed by exposing them to blue light. MNV-1 was shown to be significantly decreased in a dose-dependent manner. ${ }^{54}$

Curcumin's potential to destroy viral particles and inhibit viral replication in MNV and $\mathrm{HuNoV}$ cells (HG23) was investigated by Yang et al., 2016, wherein it was found that curcumin at different concentrations and in different time exposure showed its anti-noroviral effect in a dosedependent manner.55 Randazzo et al., 2016 evaluated the antiviral activity of photoactivated curcumin on norovirus surrogates, murine norovirus (MNV) and feline calicivirus (FCV) were evaluated and it was observed that curcumin at different compositions (13.5-1358 $\mu \mathrm{M})$ reduced the tissue culture infective dose (TCID 50 ) of FCV and $\mathrm{MuNoV}$ and it showed greater effect against FCV. The effect of photodynamically activated curcumin was greater when the concentrations of viral titers were very low and this might be due to low amount of ROS produced from the curcuminmediated photodynamic inactivation which needed to act over a larger number of viruses. ${ }^{56}$

\subsection{Respiratory Syncytial Virus}

Respiratory syncytial virus (RSV), also known as human respiratory syncytial virus (hRSV) and Human orthopneumovirus, is a highly infectious virus that infects the respiratory tract and belongs to the Pneumoviridae family. RSV is a singlestranded RNA virus with a negative sense, and its name comes from the enormous syncytia that develop when infected cells fuse together. ${ }^{57}$

Obata et al., 2013 investigated if curcumin might inhibit RSV replication, which is also an NF$\mathrm{kB}$ inhibitor, wherein the human nasal epithelial cells were pretreated with curcumin at 1 and 10 $\mu \mathrm{g} / \mathrm{ml} 30 \mathrm{~min}$ before treatment with RSV at an MOI of $10 \mu \mathrm{g} / \mathrm{ml}$ Curcumin which prevented the production of RSV/G- and M2-1-protein, which indicated the replication of the RSV. RSV replication and budding, as well as epithelial responses to it, were all reduced by curcumin 
without producing any damage. Curcumin has wide pharmacokinetic effects as an inhibitor of NF- $\kappa B$, eIF- $2 \alpha$ dephosphorylation, proteasome, and cyclooxygenase-2 (COX2). HNECs infected with RSV were exposed to the eIF- $2 \alpha$ dephosphorylation blocker salubrinal, the proteasome inhibitor MG132, and COX1 and COX2 inhibitors. The replication of RSV and epithelial responses were reduced by salubrinal, MG132, and COX2 inhibitors like curcumin, and the upregulation of tight junction molecules produced by RSV infection was addressed with salubrinal and MG132. These findings suggest that curcumin can reduce RSV replication and epithelial responses to it without causing cytotoxicity, but more research is needed to see if it can be utilized as a treatment for RSV infection in babies and young children with severe lower respiratory tract illness. ${ }^{58}$

Yang et al., 2017 loaded $\beta$-cyclodextrin (CD) functionalized graphene oxide (GO) composite with curcumin and it was observed that it showed significant anti-viral activity against RSV. Tissue culture infectious doses assay and immunofluorescence assay was performed and it revealed the curcumin-loaded graphene oxide was showing selective inhibition i.e., there was competitive inhibition to inhibit the viruses from binding to the cells. And it was observed that the Curcumin-loaded graphene sulphonated composite reduced the viral attachment in pre and post-treatment. ${ }^{59}$

\subsection{Severe Acute Respiratory Syndrome Coronavirus-2}

Curcumin and its derivatives were tested for their ability to bind to the severe acute respiratory syndrome coronavirus-2 (SARS-CoV-2) spike protein and SARS-CoV by Patel et al., 2020. It was predicted that the bis-demethoxy curcumin, compound-4, and compound-2 significantly bind to the Receptor-Binding Domain (RBD) domain of the SARS-CoV-2 spike protein and SARS-CoV spike in silico studies. Curcumin and its derivatives showed a significant molecular weight value $(\mathrm{MV}<500)$ which is essential for the remarkable penetration through the biological membranes. 60 With the help of computational modeling, simulation, and absorption, distribution, metabolism and excretion properties and Various toxicities ( $\mathrm{T}$ ) studies were done against SARSCoV-2 targets, curcumin keto and curcumin enol forms were observed as complimentary to bind with the S-glycoprotein and envelope protein of SARS-CoV-2 and with the help of binding energy, docking score, and molecular dynamic simulation, it was observed that keto form was more acceptable for the drug targets i.e., the spike glycoprotein RBD region and envelop protein. ${ }^{61}$

Wen et al., 2021 also noted that curcumin had inhibitory action when assayed with the help of cytopathogenic effect (CPE) between different range of concentrations and thus can be used in the production of antigens which can inhibit the SARS-Corona virus. ${ }^{62}$

\subsection{Vesicular Stomatitis Virus}

Vesicular stomatitis virus (VSV) is an RNA virus, member of the Rhabdoviridae family. It is an enveloped virus and various varieties of insect and mammalian cells are infected due to this virus. People infected with this virus sometimes causes mild febrile illness. ${ }^{63}$

Mounce et al., 2017 evaluated whether curcumin structural analogues could reduce the infectivity caused by VSV. Incubation was done with escalating doses of demethoxycurcumin, bisdemethoxycurcumin, EF-24, and FLLL31. It was observed that curcumin along with its structural analogues showed antiviral activity against VSV wherein demethoxy and bisdemethoxycurcumin showed similar inhibition levels as that of unmodified curcumin and with 50 or $500 \mu \mathrm{M}$ doses of EF-24 and FLLL31 reduced VSV titers up to $90 \%$. This antiviral activity exhibited by these structural analogues was due to the modification of the methoxy groups of the molecule. It was noted that VSV when incubated with curcumin and its structural analogues, the ability of the virus to bind to the cell surfaces was decreased and the infectivity was lost. 64

\subsection{Zika Virus}

Zika virus (ZIKV) is an RNA virus belonging to the family Flaviviridae and is spread by Aedes mosquitoes, such as A. aegypti and A. albopictus. 
Zika virus infection is accompanied with neurological complications such as Guillain-Barré syndrome, neuropathy and myelitis in children and adults. There is no treatment available for Zika virus infection and to the associated diseases along with it. 65

A study was done to predict the interactions between curcumin and four different potential targets of ZIKV by Kim et al., 2021. After performing a molecular docking study, it was observed that curcumin-TNF displayed the strongest binding. With the help of antiviral and plaque reduction assay, the anti-Zika effects were validated in vitro. Curcumin at a concentration range of 12.5 to $50 \mu \mathrm{M}$ showed significant antiviral activity in a dose-dependent manner $(P<.05) .66$

On ZIKV, Mounce et al., 2017 performed a timeof-addition experiment. HeLa cells were treated with $5 \mathrm{M}$ curcumin at various periods before and after infection with ZIKV, and viral filters were measured 48 hours later at MOI 0.1. When the therapy was started after the infection, it was discovered that ZIKV was susceptible to curcumin. The researchers made derivatives compounds by manipulating the chemical structure of curcumin to know about their antiviral activity and they are demetheoxycurcumin, bis-demethoxycurcumin, EF-24, FLLL31. These four compounds were incubated with ZIKV with increasing doses and these compounds exhibited antiviral activity against enveloped ZIKV. Demethoxycurcumin and bis-demethoxycurcumin showed similar inhibition levels as that of unmodified curcumin whereas EF-24 and FLLL31 showed limited antiviral activity. ${ }^{64}$

\section{CONCLUSION}

Curcumin and its equivalents have been shown to suppress the replication of a variety of RNA and DNA viruses through a variety of methods. In recent years there is large usage of curcumin in various formulations. With the increase of the demand, the growth of curcumin has increased and research is been conducted on its diverse applications. Though there are drawbacks with the bioavailability of curcumin, poor solubility, rapid metabolism, short half-life but Curcumin's effectiveness as an antiviral compound has been profoundly successful in treating different diseases. Ongoing research on curcumin and its derivatives should be further to extract the full effective antiviral properties with increased bioavailability, solubility, distribution, and low toxicity which could make its usage as a broadspectrum antiviral agent for the welfare of the human and wildlife.

Conflict of Interest: None declared.

\section{REFERENCES}

1. Chaitanya KV. Structure and Organization of Virus Genomes. Genome and Genomics. 2019 Nov;18:130.

2. Woolhouse M, Scott F, Hudson Z, Howey R, ChaseTopping M. Human viruses: discovery and emergence. Philos Trans R Soc Lond B Biol Sci. 2012 Oct 19;367(1604):2864-71.

3. Wiersinga WJ, Rhodes A, Cheng AC, Peacock SJ, Prescott HC. Pathophysiology, Transmission, Diagnosis, and Treatment of Coronavirus Disease 2019 (COVID-19). JAMA. American Medical Association (AMA);2020:782.

4. Sofowora A, Ogunbodede E, Onayade A. The role and place of medicinal plants in the strategies for disease prevention. Afr J Tradit Complement Altern Med. 2013 Aug 12;10(5):210-29.

5. Haddad PS, Azar GA, Groom S, Boivin M. Natural health products, modulation of immune function and prevention of chronic diseases. Evid Based Complement Alternat Med. 2005 Dec;2(4):513-20.

6. Lee $\mathrm{WH}$, Loo CY, Bebawy M, Luk F, Mason RS, Rohanizadeh R. Curcumin and its derivatives: their application in neuropharmacology and neuroscience in the 21st century. Curr Neuropharmacol. 2013 Jul;11(4):338-78.

7. Ahmad RS, Hussain MB, Sultan MT, Arshad MS, Waheed M, Shariati MA, Plygun S, Hashempur MH. Biochemistry, Safety, Pharmacological Activities, and Clinical Applications of Turmeric: A Mechanistic Review. Evid Based Complement Alternat Med. 2020 May 10;2020:7656919.

8. Sharifi-Rad J, Rayess YE, Rizk AA, Sadaka C, Zgheib R, Zam W, Sestito S, Rapposelli S, Neffe-Skocińska 
K, Zielińska D, Salehi B, Setzer WN, Dosoky NS, Taheri Y, El Beyrouthy M, Martorell M, Ostrander EA, Suleria HAR, Cho WC, Maroyi A, Martins N. Turmeric and Its Major Compound Curcumin on Health: Bioactive Effects and Safety Profiles for Food, Pharmaceutical, Biotechnological and Medicinal Applications. Front. Pharmacol. 2020 Sep;11:01021.

9. Hewlings SJ, Kalman DS. Curcumin: A Review of Its Effects on Human Health. Foods. 2017 Oct 22;6(10):92.

10. Moghadamtousi SZ, Kadir HA, Hassandarvish P, Tajik H, Abubakar S, Zandi K. A review on antibacterial, antiviral, and antifungal activity of curcumin. Biomed Res Int. 2014;2014:186864.

11. Sui Z, Salto R, Li J, Craik C, Ortiz de Montellano PR. Inhibition of the HIV-1 and HIV-2 proteases by curcumin and curcumin boron complexes. Bioorg Med Chem. 1993 Dec;1(6):415-22.

12. Sharma RA, Gescher AJ, Steward WP. Curcumin: the story so far. Eur J Cancer. 2005 Sep;41(13):195568.

13. Silva JVJ Jr, Ludwig-Begall LF, Oliveira-Filho EF, Oliveira RAS, Durães-Carvalho R, Lopes TRR, Silva DEA, Gil LHVG. A scoping review of Chikungunya virus infection: epidemiology, clinical characteristics, viral co-circulation complications, and control. Acta Trop. 2018 Dec;188:213-224.

14. von Rhein C, Weidner T, Henß L, Martin J, Weber C, Sliva K, Schnierle BS. Curcumin and Boswellia serrata gum resin extract inhibit chikungunya and vesicular stomatitis virus infections in vitro. Antiviral Res. 2016 Jan;125:51-7.

15. Murugesan A, Manoharan M. Dengue Virus. Emerging and Reemerging Viral Pathogens. 2020:281-359.

16. Balasubramanian A, Pilankatta $R$, Teramoto $T$, Sajith AM, Nwulia E, Kulkarni A, Padmanabhan R. Inhibition of dengue virus by curcuminoids. Antiviral Res. 2019 Feb;162:71-78.

17. Lim L, Dang M, Roy A, Kang J, Song J. Curcumin Allosterically Inhibits the Dengue NS2B-NS3 Protease by Disrupting Its Active Conformation. ACS Omega. 2020 Sep 29;5(40):25677-25686.

18. Lima AR, Silva J, Bezerra LL, Marinho MM, Marinho ES. Molecular docking of potential curcuminoids inhibitors of the NS1 protein of dengue virus. Int J Sci Eng Res. 2017 July;8(4):2238-2242.

19. Marbawati D, Umniyati SR. Effects of Curcumin and Pentagamavunon-0 Against Dengue-2 Virus Infect- ion in Vero Cells; an in vitro Study. Procedia Environ Sci. 2015;23:215-221.

20. Carneiro SS, Braz HL, Silva J, Filho De Morais CL, Marinho MM, Marinho ES. Study of the interactional properties between Curcumin/Monodimethylcurcumin andprotein (NS1) of dengue fever virus type 4 (DENV4). Int J Sci Eng Res Vol. 2017 July;8(7):2238-2243.

21. Ichsyani M, Ridhanya A, Risanti M, Desti H, Ceria R, Putri DH, Sudiro TM, Dewi BE. Antiviral effects of Curcuma longa L. against dengue virus in vitro and in vivo. IOP Conf Ser Earth Environ Sci. 2017;101(1).

22. Hasan S, Ahmad SA, Masood R, Saeed S. Ebola virus: A global public health menace: A narrative review. J Family Med Prim Care. 2019 Jul;8(7):2189-2201.

23. Sordillo PP, Helson L. Curcumin suppression of cytokine release and cytokine storm. A potential therapy for patients with Ebola and other severe viral infections. In vivo. 2015 Jan-Feb;29(1):1-4.

24. Abe Y, Hashimoto S, Horie T. Curcumin inhibition of inflammatory cytokine production by human peripheral blood monocytes and alveolar macrophages. Pharmacol Res. 1999 Jan;39(1):41-7.

25. Noor A, Gunasekaran S, Vijayalakshmi MA. Improvement of Insulin Secretion and Pancreatic $\beta$-cell Function in Streptozotocin-induced Diabetic Rats Treated with Aloe vera Extract. Pharmacognosy Res. 2017 Dec;9(Suppl 1):S99S104.

26. Whitley RJ. Herpesviruses. In: Baron S, editor. Medical Microbiology. 4th edition. Galveston (TX): University of Texas Medical Branch at Galveston; 1996. 68. Available from: https://www.ncbi.nlm.nih.gov/books/NBK8157/

27. Hergenhahn M, Soto U, Weninger A, Polack A, Hsu $\mathrm{CH}$, Cheng $\mathrm{AL}$, Rösl F. The chemopreventive compound curcumin is an efficient inhibitor of Epstein-Barr virus BZLF1 transcription in Raji DRLUC cells. Mol Carcinog. 2002 Mar;33(3):137-45.

28. Liu L, Yang J, Ji W, Wang C. Curcumin Inhibits Proliferation of Epstein-Barr Virus-Associated Human Nasopharyngeal Carcinoma Cells by Inhibiting EBV Nuclear Antigen 1 Expression. Biomed Res Int. 2019 Oct 7;2019:8592921.

29. Mehta P, Reddivari AKR. Hepatitis. In: StatPearls. Treasure Island (FL): StatPearls Publishing; 2021 Jan. Available

from: https://www.ncbi.nlm.nih.gov/books/NBK554549 30. Patwardhan M, Morgan MT, Dia V, D'Souza DH. 
Heat sensitization of hepatitis A virus and Tulane virus using grape seed extract, gingerol and curcumin. Food Microbiol. 2020 Sep;90:103461.

31. Kim HJ, Yoo HS, Kim JC, Park CS, Choi MS, Kim M, Choi H, Min JS, Kim YS, Yoon SW, Ahn JK. Antiviral effect of Curcuma longa Linn extract against hepatitis $\mathrm{B}$ virus replication. J Ethnopharmacol. 2009 Jul 15;124(2):189-96.

32. Wei ZQ, Zhang YH, Ke CZ, Chen HX, Ren P, He YL, $\mathrm{Hu}$ P, Ma DQ, Luo J, Meng ZJ. Curcumin inhibits hepatitis $\mathrm{B}$ virus infection by down-regulating cccDNA-bound histone acetylation. World J Gastroenterol. 2017 Sep 14;23(34):6252-6260.

33. Wang HX, Liu M, Weng SY, Li JJ, Xie C, He HL, Guan W, Yuan YS, Gao J. Immune mechanisms of Concanavalin A model of autoimmune hepatitis. World J Gastroenterol. 2012 Jan 14;18(2):119-25.

34. Kim K, Kim KH, Kim HY, Cho HK, Sakamoto N, Cheong J. Curcumin inhibits hepatitis $\mathrm{C}$ virus replication via suppressing the Akt-SREBP-1 pathway. FEBS Lett. 2010 Feb 19;584(4):707-12.

35. Whitley R, Baines J. Clinical management of herpes simplex virus infections: past, present, and future. F1000Res. 2018 Oct 31;7:F1000 Faculty Rev-1726.

36. Kutluay SB, Doroghazi J, Roemer ME, Triezenberg SJ. Curcumin inhibits herpes simplex virus immediate-early gene expression by a mechanism independent of p300/CBP histone acetyltransferase activity. Virology. 2008 Apr 10;373(2):239-47.

37. Flores DJ, Lee LH, Adams SD. Inhibition of Curcumin-Treated Herpes Simplex Virus 1 and 2 in Vero Cells. Adv Microbiol. 2016;06(04):276-287.

38. Zandi K, Ramedani E, Mohammadi K, Tajbakhsh S, Deilami I, Rastian Z, Fouladvand M, Yousefi F, Farshadpour F. Evaluation of antiviral activities of curcumin derivatives against HSV-1 in Vero cell line. Nat Prod Commun. 2010 Dec;5(12):1935-8.

39. Ferreira VH, Nazli A, Dizzell SE, Mueller K, Kaushic C. The anti-inflammatory activity of curcumin protects the genital mucosal epithelial barrier from disruption and blocks replication of HIV-1 and HSV-2. PLoS One. 2015 Apr 9;10(4):e0124903.

40. Ghebremedhin B. Human adenovirus: Viral pathogen with increasing importance. Eur J Microbiol Immunol (Bp). 2014 Mar;4(1):26-33. doi: 10.1556/EuJMI.4.2014.1.2. Epub 2014 Mar 14.

41. Jennings MR, Parks RJ. Antiviral Effects of Curcumin on Adenovirus Replication. Microorganisms, 2020 Oct 4;8(10):1524.
42. Gugliesi F, Coscia A, Griffante G, Galitska G, Pasquero S, Albano C, Biolatti M. Where do we Stand after Decades of Studying Human Cytomegalovirus? Microorganisms. 2020 May 8;8(5):685.

43. Lv Y, Gong L, Wang Z, Han F, Liu H, Lu X, Liu L. Curcumin inhibits human cytomegalovirus by downregulating heat shock protein 90. Mol Med Rep. 2015 Sep;12(3):4789-4793.

44. Lv Y, An Z, Chen H, Wang Z, Liu L. Mechanism of curcumin resistance to human cytomegalovirus in HELF cells. BMC Complement Altern Med. 2014 Aug 4;14:284.

45. Lv YL, Jia Y, Wan Z, An ZL, Yang S, Han FF, Gong LL, Xuan LL, Ren LL, Zhang W, Liu H, Liu LH. Curcumin inhibits the formation of atherosclerosis in $\mathrm{ApoE}^{-/-}$ mice by suppressing cytomegalovirus activity in endothelial cells. Life Sci. 2020 Sep 15;257:117658.

46. Durand S, Cimarelli A. The inside out of lentiviral vectors. Viruses. 2011 Feb;3(2):132-59.

47. Barthelemy S, Vergnes L, Moynier M, Guyot D, Labidalle S, Bahraoui E. Curcumin and curcumin derivatives inhibit Tat-mediated transactivation of type 1 human immunodeficiency virus long terminal repeat. Res Virol. 1998 JanFeb;149(1):43-52.

48. Kumari N, Kulkarni AA, Lin X, McLean C, Ammosova $T$, Ivanov $A$, Hipolito $M$, Nekhai $S$, Nwulia E. Inhibition of HIV-1 by curcumin A, a novel curcumin analog. Drug Des Devel Ther. 2015 Sep 3;9:5051-60.

49. Gheit T. Mucosal and Cutaneous Human Papillomavirus Infections and Cancer Biology. Front. Oncol. 2019 May 08;9:355.

50. Divya CS, Pillai MR. Antitumor action of curcumin in human papillomavirus associated cells involves downregulation of viral oncogenes, prevention of NFkB and AP-1 translocation, and modulation of apoptosis. Mol Carcinog. 2006 May;45(5):320-32.

51. Mesri EA, Cesarman E, Boshoff C. Kaposi's sarcoma and its associated herpesvirus. Nat Rev Cancer. 2010 Oct;10(10):707-19.

52. Li H, Zhong C, Wang Q, Chen W, Yuan Y. Curcumin is an APE1 redox inhibitor and exhibits an antiviral activity against KSHV replication and pathogenesis. Antiviral Res. 2019 Jul;167:98-103.

53. Robilotti E, Deresinski S, Pinsky BA. Norovirus. Clin Microbiol Rev. 2015 Jan;28(1):134-64.

54. Wu J, Hou W, Cao B, Zuo T, Xue C, Leung AW, Xu C, Tang QJ. Virucidal efficacy of treatment with 
photodynamically activated curcumin on murine norovirus bio-accumulated in oysters. Photodiagnosis Photodyn Ther. 2015 Sep;12(3):385-92.

55. Yang M, Lee G, Si J, Lee SJ, You HJ, Ko G. Curcumin Shows Antiviral Properties against Norovirus. Molecules. 2016 Oct 20;21(10):1401.

56. Randazzo W, Aznar R, Sánchez G. CurcuminMediated Photodynamic Inactivation of Norovirus Surrogates. Food Environ Virol. 2016 Dec;8(4):244-250.

57. Griffiths C, Drews SJ, Marchant DJ. Respiratory Syncytial Virus: Infection, Detection, and New Options for Prevention and Treatment. Clin Microbiol Rev. 2017 Jan;30(1):277-319.

58. Obata K, Kojima T, Masaki T, Okabayashi T, Yokota S, Hirakawa S, Nomura K, Takasawa A, Murata M, Tanaka S, Fuchimoto J, Fujii N, Tsutsumi H, Himi T, Sawada N. Curcumin prevents replication of respiratory syncytial virus and the epithelial responses to it in human nasal epithelial cells. PLoS One. 2013 Sep 18;8(9):e70225.

59. Yang XX, Li CM, Li YF, Wang J, Huang CZ. Synergistic antiviral effect of curcumin functionalized graphene oxide against respiratory syncytial virus infection. Nanoscale. 2017 Sep 20;9(41):16086-16092.

60. Patel A, Rajendran M, Shah A, Patel H, Pakala SB, Karyala P. Virtual screening of curcumin and its analogs against the spike surface glycoprotein of SARS-CoV-2 and SARS-CoV. J Biomol Struct Dyn. 2021 Jan 5:1-9.

61. Shanmugarajan D, Prashantha Kumar BR, Suresh B. Curcumin to inhibit binding of spike glycoprotein to ACE2 receptors: computational modelling, simulations, and ADMET studies to explore curcuminoids against novel SARS-CoV-2 targets. RSC Adv. 2020 Aug 25,10:31385-31399.

62. Wen CC, Kuo YH, Jan JT, Liang PH, Wang SY, Liu HG, Lee CK, Chang ST, Kuo CJ, Lee SS, Hou CC, Hsiao PW, Chien SC, Shyur LF, Yang NS. Specific plant terpenoids and lignoids possess potent antiviral activities against severe acute respiratory syndrome coronavirus. J Med Chem. 2007 Aug 23;50(17):4087-95.

63. Strauss Jh, Strauss Eg. Minus-Strand RNA Viruses. Viruses and Human Disease. 2008:137-91.

64. Mounce BC, Cesaro T, Carrau L, Vallet T, Vignuzzi M. Curcumin inhibits Zika and chikungunya virus infection by inhibiting cell binding. Antiviral Res. 2017 Jun;142:148-157.

Cite the Article as: Rathnakar P, Manipriya K, Ashritha A. Curcumin: A Potent Polyphenol with Broad Inhibitory Effect against Different Viral Diseases. J Drug Vigil Altern Ther. 2021 June 30;1(2):65-77.

\section{www.jdvat.org}

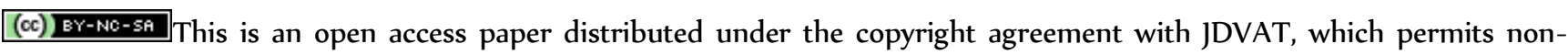
commercial unrestricted use, distribution, and reproduction in any medium or format, provided the original work is properly cited. 